Research paper/Оригинальная статья

https://doi.org/10.51176/1997-9967-2021-4-143-159

МРНТИ 06.52.17

JEL: C12, C51, I38, J14, R29

Check for updates

(cc) BY-NC 4.0

\title{
Single-Parent Families with Disabilities as an Object of Structural Modeling
}

\author{
Tatyana P. Pritvorova ${ }^{1}$, Assiya K. Atabayeva ${ }^{1 *}$, Yelena S. Petrenko ${ }^{2}$ \\ ${ }^{1}$ Karaganda university after E.A. Buketov, 28 Universitetskaya Str., 100000, Karaganda, Kazakhstan \\ ${ }^{2}$ Plekhanov Russian University of Economics, 36 Stremyanny Lane, 117997, Moscow, Russia
}

\begin{abstract}
The status of a single-parent family and the upbringing of a child with a disability generate social risks in most countries of the world. The article is aimed at identifying significant factors that determine the limitations of the human capital development possibilities in a single-parent family with disabled children in Kazakhstan. The authors applied the method of sociological survey of respondents in five regions of Kazakhstan. The interview is based on the methodology of international research, based on the allocation of four types of restrictions: direct costs per child, indirect losses of the household, assessment of the opportunity for the parent to find employment, and maintaining of his health. The results of the survey were processed by the method of structural modeling using the PLS-PM model, which includes four dependent variables. Single-parent families estimate the importance of benefits for a direct child costs four times higher than full families since a third of these families live only on transfers. Care allowances are considered by the parent in terms of replacing lost income, but the amount of the benefit is not related to the amount of care for the child. A parent in a single-parent family, more often than in a full one, connects his estimated long-term costs for the child's future (vocational education) with indirect losses of the family. A statistically significant negative relationship between the available services (public or state-subsidized) for the parent in the field of physiological/ psychological health and his ability to maintain his health was revealed.
\end{abstract}

Keywords: households, child with a disability, family capacity limitations, PLS-PM model, factors

For citation: Pritvorova, T.P., Atabayeva, A.K. \& Petrenko, Y.S. (2021). Single-Parent Families with Disabilities as an oBject of Structural Modeling. Economics: the Strategy and Practice, 16(4), 143-159, https://doi.org/10.51176/19979967-2021-4 -143-159

* Corresponding author: Atabayeva A.K. - PhD student, Karaganda University named after E.A. Buketov, 28 Universitetskaya str., 100000, Karaganda, Kazakhstan, 87013295110, e-mail: asiaatabaeva@gmail.com

Conflict of interests: the authors declare that there is no conflict of interest.

Financial support: The results of the study were obtained as part of a grant funding project supported by the Science Committee of the Ministry of Education and Science of the Republic of Kazakhstan, "The support system for households with disabled children: conceptual framework, effective practices, development mechanisms in Kazakhstan", 20202022. Registration number: AP0880566.

The article received: 25.06 .2021

The article approved for publication: 21.07. 2021

Date of publication: 30.12 .2021 


\title{
Мүмкіндігі шектеулі жалғыз басты отбасылар құрылымдық модельдеу объектісі ретінде
}

\author{
Притворова Т.П. ${ }^{1}$, Атабаева А.К.. ${ }^{1 *}$, Петренко Е.С. ${ }^{2}$ \\ ${ }^{1}$ Е.А.Бөкетов атындавы Қараванды университеті, Университетская к., 28, 100000, \\ Қараванды, Қазақстан \\ ${ }^{2}$ Г.В. Плеханов атындавы Ресей экономика университеті, Стремянный ж., 36, 117997, \\ Мәскеу Ресей
}

\section{Түйін}

Дүние жүзінің көптеген елдерінде жалғыз басты отбасының мәртебесі және мүгедек баланы тәрбиелеу әлеуметтік қауіптерді тудырады. Мақаланың мақсаты Қазақстандағы мүгедек балалары бар толық емес отбасында адами капиталды дамыту мүмкіндіктерінің шектеулерін анықтайтын маңызды факторларды анықтау болды. Авторлар Қазақстанның бес аймағындағы респонденттерге социологиялық сауалнама жүргізу әдісін қолданды. Әңгімелесу халықаралық зерттеу әдістемесіне негізделген, шектеулердің төрт түрін анықтауға негізделген: бір балаға шаққандағы тікелей шығындар, үй шаруашылығындағы жанама шығындар, ата-ананың жұмысқа орналасу және денсаулығын сақтау мүмкіндігін бағалау. Сауалнама нәтижелері төрт тәуелді айнымалыны қамтитын PLS-PM үлгісін қолдану арқылы құрылымдық модельдеу арқылы өңделді. Толық емес отбасылар баланың тікелей құны бойынша жәрдемақы құнын бағалауда толық отбасылардан төрт есе жоғары, өйткені бұл отбасылардың үштен бірі тек трансфертпен тұрады. Күтім бойынша жәрдемақыны ата-ана жоғалтқан табыстың орнын толтыру үшін қарастырады, бірақ жәрдемақының мөлшері бала күтімінің мөлшеріне байланысты емес. Толық емес жанұядағы ата-ана көбінесе толық отбасына қарағанда баланың болашағына (кәсіптік білім беру) ұзақ мерзімді шығындары мен жанұяның жанама шығындарын байланыстырады. Ата-анаға физиологиялық/психологиялық денсаулық саласындағы қолжетімді қызметтер (мемлекеттік немесе мемлекет тарапынан субсидияланатын) мен оның денсаулығын сақтау қабілеті арасында статистикалық маңызды теріс байланыс анықталды.

Түйін сөздер: үй шаруашылықтары, мүгедек баласы бар отбасы, отбасы мүмкіндіктерінің шектеулері, PLS-PM моделі, факторлар

Дәйексөз алу үшін: Притворова Т.П., Атабаева А.Қ., Петренко Е.С. (2021). Мүмкіндігі шектеулі жалғыз басты отбасылар құрылымдық модельдеу объектісі ретінде. Экономика: стратегия және тәжірибе, 1Экономика: стратегия және практика, 16(4), 143-159, https://doi.org/10.51176/1997-9967-2021-4 -143-159

* Хат-хабаршы авторы: Атабаева А.Қ. - PhD-докторант, Е.А.Бөкетов атындағы Қарағанды университеті, Қазақстан, Университетская к., 28, 100000, Қарағанды, Қазақстан, 87013295110, e-mail: szt_kz@mail.ru

Мүдделер қақтығысы: авторлар мүдделер қақтығысының жоқтығын мәлімдейді.

Қаржыландыру. Зерттеу нәтижелері Қазақстан Республикасы Білім және ғылым министрлігі Ғылым комитетінің қолдауымен гранттық қаржыландыру жобасы аясында алынған «Мүгедек балалары бар үй шаруашылықтарын қолдау жүйесі: тұжырымдамалық негіз, тиімді тәжірибелер, даму тетіктері. Қазақстанда», 2020-2022 жж. Тіркеу нөмірі: АР0880566.

Мақала редакцияға түсті: 25.06 .2021

Жариялау туралы шешім қабылданды: 21.07 .2021

Жарияланды: 30.12 .2021 


\title{
Неполные семьи с ограниченными возможностями как объект структурного моделирования
}

\author{
Притворова Т.П. ${ }^{1}$, Атабаева А.К. ${ }^{1 *}$, Петренко Е.С. ${ }^{2}$ \\ ${ }^{1}$ Карагандинский университет имени Е.А. Букетова, ул. Университетская, 28, 100000, \\ Караганда, Казахстан \\ ${ }^{2}$ Российский экономический университет им. Г.В. Плеханова, Стремянный пер., 36, \\ 117997, Москва, Россия
}

\begin{abstract}
Аннотация
Статус семьи с одним родителем и воспитание ребенка с инвалидностью генерирует социальные риски в большинстве стран мира. Целью статьи стало выявление значимых факторов, определяющих ограничения возможностей развития человеческого капитала в неполной семье с детьми-инвалидами в Казахстане. Авторами применен метод социологического опроса респондентов в пяти регионах Казахстана. В основу интервью положена методология международных исследований, основанная на выделении четырех видов ограничений: прямые затраты на ребенка, косвенные потери домохозяйства, оценка возможности для родителя обрести занятость и поддержать свое здоровье. Результаты опроса обработаны методом структурного моделирования с применением модели PLS-PM, которая включает четыре зависимые переменные. Неполные семьи в четыре раза выше, чем полные, оценивают значение пособий для прямых затрат на ребенка, т.к. треть этих семей живет только на трансферты. Пособия по уходу рассматриваются родителем с точки зрения замещения утраченного дохода, но размер пособия не соотносится с объемом ухода за ребенком. Родитель в неполной семье, чаще, чем в полной, связывает предполагаемые им долгосрочные расходы на будущее ребенка (профобразование) и косвенные потери семьи. Выявлена статистически значимая отрицательная связь между доступными услугами (государственными или субсидируемыми государством) для родителя в области здоровья физиологического/психологического и его возможностью поддерживать свое здоровье.
\end{abstract}

Ключевые слова: домохозяйства с одним взрослым и ребенком с инвалидностью, ограничения возможностей семьи, модель PLS-PM, факторы

Для цитирования: Притворова Т.П., Атабаева А.К., Петренко Е.С (2021). Неполные семьи с ограниченными возможностями как объект структурного моделирования. Экономика: стратегия и практика, 16(4), 143-159, https://doi.org/10.51176/1997-9967-2021-4-143-159

* Корреспондирующий автор: Атабаева А.К. - PhD-докторант, Карагандинский университет им. Е.А.Букетова, ул. Университетская 28, 100000, Караганда, Казахстан, 87013295110, e-mail: asiaatabaeva@gmail. com

Конфликт интересов: авторы заявляют об отсутствии конфликта интересов.

Финансирование. Результаты исследования получены в рамках проекта грантового финансирования, поддержанного Комитетом науки Министерства образования и науки РК, «Система поддержки домохозяйств с детьми-инвалидами: концептуальные основы, эффективные практики, механизмы развития в Казахстане», 2020-2022 гг. Регистрационный номер: АР0880566.

Статья поступила в редакцию: 25.06 .2021

Принято решение о публикации: 21.07 .2021

Опубликовано: 30.12 .2021 


\section{Введение}

Домохозяйства с детьми-инвалидами выделяются как объект исследований с точки зрения демографических, социальных, экономических параметров с 1970-х годов. Исследователи, а вслед за ними и практики, утверждаются во мнении, что рождение ребенка с инвалидностью оказывает влияние на финансовые, социальные, психологические и другие ресурсы семьи. В таких семьях нередко отмечается нестандартная форма занятости родителей, ухудшение их карьерных возможностей, высокие затраты на поддержание физиологического и психического здоровья членов семьи. В социальной политике государства начинает выделяться особый тип домохозяйства, который идентифицируется как «семья с ограниченными возможностями» развития человеческого потенциала своих членов [1].

Понятие «неполная семья» в международной статистике определяется как «дети с одним родителем». Неполные семьи среди всех домохозяйств с детьми в странах ОЭСР в 2011 году составляли: в Латвии $36,6 \%$, США - 32,1\%, Великобритании - 27,6\%. По Еврозоне в целом эти домохозяй-ства в 2011 году составили 20,6\% совокупности [2]. В среднем за период с 2003 по 2018 год доля детей, проживающих в неполных семьях Латвии, составила 30,1\%, в США - 26,9\%, Бельгии и Дании по 23\% [3].

На 2018 год для семей с одним родителем в 24 странах из 30, по которым в статистической базе ОЭСР есть данные, выплачивается целевое пособие, критерием которого является статус семьи с одним родителем. В 13 странах из 24 (55\%) пособие проверяется на размер среднедушевых доходов в домохозяйстве. Лидерами в области поддержки неполных семей являются Польша и Германия, размеры пособий в которых 36,5 \% и 29\% к средней заработной плате по стране. Аутсайдерами выглядят США - 0,6\% и Испания - 2,2\% [4].

Выплата адресных пособий по критерию «статус неполной семьи» отражает её повышенные риски в социально-экономическом пространстве. Дополнительным риском для такой семьи является инвалидность ребенка.

Масштабы бедности среди всех домохозяйств с детьми-инвалидами, как правило, выше, чем у обычных семей с детьми. Превышение составляет в Португалии 11,9\%, США - 11,2\%, Словении - 6,7\%. Но в некоторых странах меры поддержки формируют обратное соотношение: в Германии, Норвегии, Швеции доля бедных выше среди обычных домохозяйств с детьми. Пособие по уходу за ребенком с инвалидностью в неполной семье, как правило, выше, чем у семьи с 2 родителями. Например, в Австралии на 30\%, в Венгрии - на 11\%. Пособие может проверяться на доход [5].

В Казахстане 8,3\% семей с детьми имеют в своем составе одного взрослого [6]. Но данные о количестве семей с одним взрослым, имеющих в составе детей с инвалидностью, в официальной казахстанской статистике пока отсутствуют. Нет и адресных пособий для неполных семей, воспитывающих детей с инвалидностью. В то время как в нашей выборке из 301 домохозяйства с ограниченными возможностями в 5 регионах (8 городах и 7 районах) Казахстана таких семей оказалось $26 \%$.

Учитывая, что получателей пособий по уходу за ребенком-инвалидом в 2019 году было 85229 человек [7], речь идет, как минимум, о 22160 взрослых, чье социально-экономическое положение ещё более уязвимо, чем у семей с двумя взрослыми в аналогичном типе семьи.

\section{Литературный обзор}

Исследование возможностей развития человеческого капитала в неполных семьях помещает в фокус несколько характеристик: экономическое положение, занятость родителя, жизненные результаты (статус, самореализация, личная жизнь).

На экономических факторах благополучия сосредоточены исследования Форри Н., Стэк Р., Мередит А., Браун С., Маннинг Щ., Стыкес Й. и др.

В работе Форри Н. подтверждено, что субсидии по уходу за детьми возмещают прямые затраты родителей на уход за ребенком и повышают финансовое благополучие семьи в целом, её возможность оплачивать счета за жилье [8]. Применение тематического анализа позволило Стэк Р., Мередит А. выявить проблему продовольственной бедности и затруднения оплаты коммунальных услуг, реализации жизненной стратегии выживания и отказа взрослых от удовлетворения своих потребностей [9]. В частности, подчеркивается недостаточность только психологической помощи для улучшения положения таких семей и предлагается уделять больше внимания экономическим ресурсам семьи. Результаты исследования в работе Хайнц-Мартин В., Лангмайер А. [10] однозначно показывают, что неполные семьи и дети в таких семьях подвержены большему риску попадания за порог бедности. В исследовании Браун С., Маннинг Щ., Стыкес Й. также получено подтверждение того факта, что в неполных 
семьях часто отмечается более низкий уровень удовлетворения потребностей по сравнению с полной семьей [11].

Ряд исследований сосредоточен на состоянии здоровья и социальных проблемах членов неполных семей, которые объясняются более высокими показателями бедности, например, в работе Кэмпбелл М., Томсон Х., Фентон К. [12].

Перри-Дженкинс М., Гиллман С. подчеркивают, что оценка воздействия результатов занятости на социально-экономическое благополучие в неполных семьях, в сравнении с полными семьями, не имеет однозначных и статистически надежных результатов, т.к., по их мнению, большее значение имеют социальный контекст и характеристики человека [13].

В мировой литературе представлены также исследования обобщенного характера, которые, как например Геннетиан Л., делают попытки установить связь между характеристиками семьи (в том числе неполной) и достижениями детей в учебе [14]. В работах Харконен Д., Бернарди Ф., Боертин Д. [15], Мариани Е., Озкан Б., Гоизис А. [16], Радл Д., Салазар Л., Себолла-Боадо X. [17] систематизированы результаты по исследованиям последствий динамики семьи для благополучия детей и шансов на жизнь. В работе Мариани Е. показаны результаты первого европейского анализа жизненных траекторий детей, рожденных от матерейодиночек. В работе Радл Д. рассматривается включение в неполную семью старшего поколения и влияние этого на результаты детей.

Неполные семьи, воспитывающие детей с инвалидностью, имеют как минимум две характеристики, усложняющие их социальноэкономическое положение. По мнению исследователей Пенне Т., Хуфкенс Т., Гоедеме Т., Стормс Б. [18], Гуллинан Дж., Ганнон Б., Лионс С. [19], Митра С. [20], инвалидность ребенка с одним родителем однозначно помещает семью в зону высокой нестабильности.

Оценка возможностей развития человеческого капитала в таких семьях позволяет с уверенностью утверждать, что их характеризует:

- Бедность вследствие ограниченных ресурсов семьи, в том числе по причине более частых разводов по сравнению с обычными семьями [21-24].

- Безработица или неполная, часто низкооплачиваемая, занятость у родителей и детей в экономически активном возрасте [2526].
Оценка последствий от ограничений возможностей семьи в связи с рождением ребенка-инвалида проводится через призму её финансовых ресурсов, здоровья и самореализации всех членов семьи, то есть возможностей формирования и реализации человеческого капитала [27-28].

В состав ограничений для семьи с ребенком-инвалидом включают следующие четыре характеристики:

1. Прямые расходы «из своего кармана» на медицинские, психологические, образовательные и другие реабилитационные услуги для ребенка. Объем необходимых услуг связан с типом инвалидности и её тяжестью. На доступность услуг влияет их цена, доходы семьи, доступность государственных услуг и льготы (в том числе пособия). Сопряженными с прямыми затратами являются затраты на обеспечение доступности жилья, размещение оборудования для терапии [29-32].

2. Косвенные затраты семьи, которые рассматривают как потери, которые несут родители вследствие невозможности поддерживать полноформатную занятость и здоровье, которые они имели бы в случае рождения ребенка без ограничений в развитии [33].

3. Возможность реализации потенциала членов семьи (родителей и ребенка) в занятости [34-35].

4. Ухудшение здоровья родителей, связанное с комплексом проблем, возникающих после рождения ребенка с инвалидностью [36-37].

Поскольку круг проблем у семьи с детьми-инвалидами достаточно велик, то в современных странах ей оказывается целый комплекс взаимоувязанных мер, направленных на компенсацию, нейтрализацию или предупреждение ограничений (которые могут рассматриваться как рисковые ситуации) [3841].

Новизна нашего исследования заключается в том, что нами адаптирована международная методология оценки ограничений в возможностях у семьи с детьми-инвалидами к условиям Казахстана. В фокусе исследования находится семья в целом, в то время как проводимые до сих пор статистические опросы, в том числе по линии ЮНИСЕФ, сосредоточены на нуждах детей с инвалидностью. Применение структурной модели PLS-PM позволило нам выявить факторы, имеющие значимое влияние на четыре ограничения возможностей развития человеческого капитала в неполных семьях с детьми-инвалидами: прямые затраты на 
ребенка, косвенные потери семьи, возможность поддерживать здоровье родителя, возможность занятости родителя. Способность структурной модели рассматривать в составе фактора систему из нескольких индикаторов дали возможность описывать фактор с помощью комплекса признаков, а не каждый из них в отдельности.

Целью статьи стало выявление значимых факторов, определяющих ограничения возможностей развития человеческого капитала в неполных семьях с детьми-инвалидами в Казахстане.

\section{Методология}

Нами применен метод социологического опроса с последующей обработкой результатов с помощью структурной модели PLSPM, реализованной с помощью программы SmartPLS.

Социологический опрос был проведен в пяти регионах Казахстана: Карагандинской, Акмолинской, Восточно-Казахстанской, Павлодарской и Алматинской областях в форме телефонных опросов и фокус групп в кабинетах психолого-педагогической коррекции. Объем выборки составил 301 респондент, из которых 78 представляют неполные семьи.

В опросный лист были включены 4 зависимые и 8 независимых переменных и составляющие их индикаторы, каждый из которых оценивался по 5-балльной шкале (таблица 1)

Таблица 1 - Условные обозначения переменных в модели PLS-PM Table 1 - Symbols of variables in the PLS-PM model

\begin{tabular}{|c|c|c|c|c|}
\hline № & Переменные & $\begin{array}{l}\text { Обозна- } \\
\text { чение }\end{array}$ & Индикаторы & $\begin{array}{l}\text { Обозначе- } \\
\text { ние в модели }\end{array}$ \\
\hline 1 & 2 & 3 & 4 & 5 \\
\hline \multirow[t]{3}{*}{1} & \multirow{3}{*}{$\begin{array}{l}\text { Возможность поддерживать } \\
\text { здоровье родителя /The ability to } \\
\text { stay healthy }\end{array}$} & \multirow[t]{3}{*}{ Y1 } & $\begin{array}{l}\text { Доступность психологических } \\
\text { консультаций }\end{array}$ & Y15health \\
\hline & & & $\begin{array}{l}\text { Доступность общеоздоровительных } \\
\text { услуг }\end{array}$ & Y14health \\
\hline & & & Доступность медицинских услуг & Y13health \\
\hline \multirow[t]{3}{*}{2} & \multirow{3}{*}{$\begin{array}{l}\text { Возможность работать для } \\
\text { родителя/ Opportunity to work }\end{array}$} & \multirow[t]{3}{*}{ Y2 } & Возможность полной занятости & Y10opwork \\
\hline & & & Возможность частичной занятости & Y11opwork \\
\hline & & & Возможность самозанятости & Y12opwork \\
\hline \multirow[t]{3}{*}{3} & \multirow{3}{*}{$\begin{array}{l}\text { Косвенные потери семьи/ Indirect } \\
\text { family losses }\end{array}$} & \multirow{3}{*}{ Y3 } & Потеря дохода семьи & Y7indloss \\
\hline & & & $\begin{array}{l}\text { Затраты на дополнительные услуги } \\
\text { для семьи }\end{array}$ & Y8indloss \\
\hline & & & $\begin{array}{l}\text { Платные услуги «длительной } \\
\text { передышки» (отпуска) }\end{array}$ & Y9indloss \\
\hline \multirow[t]{6}{*}{4} & \multirow{6}{*}{$\begin{array}{l}\text { Прямые затраты на ребенка/ Di- } \\
\text { rect costs for a child }\end{array}$} & \multirow{6}{*}{ Y4 } & $\begin{array}{l}\text { Финансовое «бремя» из-за } \\
\text { инвалидности ребенка в целом }\end{array}$ & Y1dcosts \\
\hline & & & $\begin{array}{l}\text { Уровень затрат на медицинские } \\
\text { услуги и средства }\end{array}$ & Y2dcosts \\
\hline & & & $\begin{array}{l}\text { Уровень затрат на психологические } \\
\text { услуги }\end{array}$ & Y3dcosts \\
\hline & & & $\begin{array}{l}\text { Уровень затрат на услуги } \\
\text { образования }\end{array}$ & Y4dcosts \\
\hline & & & $\begin{array}{l}\text { Уровень затрат на услуги общего } \\
\text { развития (хобби, физкультура) }\end{array}$ & Y5dcosts \\
\hline & & & Уровень сопутствующих затрат & Y6dcosts \\
\hline \multirow[t]{3}{*}{5} & \multirow{3}{*}{$\begin{array}{l}\text { Оценка (прогноз) долгосрочных } \\
\text { pacходов семьи на ребенка / Long- } \\
\text { term family expenses per child }\end{array}$} & \multirow[t]{3}{*}{$\mathrm{X} 1$} & Среднее образование & X19longexp \\
\hline & & & Профессиональное образование & X20longexp \\
\hline & & & Жилье & X21longexp \\
\hline
\end{tabular}




\begin{tabular}{|c|c|c|c|c|}
\hline 1 & 2 & 3 & 4 & 5 \\
\hline \multirow[t]{3}{*}{6} & \multirow{3}{*}{$\begin{array}{l}\text { Государственные бесплатные } \\
\text { услуги для семьи в целом/ } \\
\text { Additional government free of } \\
\text { charge family services }\end{array}$} & \multirow{3}{*}{$\mathrm{X} 2$} & $\begin{array}{l}\text { Краткосрочная «передышка» } \\
3 \text { часа } 2 \text { раза в неделю }\end{array}$ & X16govserv \\
\hline & & & $\begin{array}{l}\text { Долгосрочная «передышка» } \\
\text { 2-3 недели раз в год }\end{array}$ & X17govserv \\
\hline & & & Другие & X18govserv \\
\hline \multirow[t]{3}{*}{7} & \multirow{3}{*}{$\begin{array}{l}\text { Доступные медицинские услуги } \\
\text { для ребенка/ } \\
\text { Accessibility of health care for } \\
\text { children }\end{array}$} & \multirow{3}{*}{$\mathrm{X} 3$} & Объем услуг & X4medserv \\
\hline & & & Качество услуг & X5medserv \\
\hline & & & $\begin{array}{l}\text { Условия предоставления услуг (право } \\
\text { на получение, режим) }\end{array}$ & X6medserv \\
\hline \multirow[t]{3}{*}{8} & \multirow{3}{*}{$\begin{array}{l}\text { Доступность специальных } \\
\text { социальных услуг для ребенка/ } \\
\text { Accessibility of social services for } \\
\text { children }\end{array}$} & \multirow{3}{*}{$\mathrm{X} 4$} & Объем услуг & X7medserv \\
\hline & & & Качество услуг & X8medserv \\
\hline & & & $\begin{array}{l}\text { Условия предоставления услуг (право } \\
\text { на получение, режим) }\end{array}$ & X9medserv \\
\hline \multirow[t]{3}{*}{9} & \multirow{3}{*}{$\begin{array}{l}\text { Другие услуги для ребенка } \\
\text { согласно ИПР/ Other services for } \\
\text { the child }\end{array}$} & \multirow{3}{*}{$\mathrm{X} 5$} & Объем услуг & \begin{tabular}{|l|} 
X10othserv \\
\end{tabular} \\
\hline & & & Качество услуг & X11 othserv \\
\hline & & & Условия предоставления услуг & X12 othserv \\
\hline \multirow[t]{3}{*}{10} & \multirow{3}{*}{$\begin{array}{l}\text { Затраты времени членов семьи на } \\
\text { уход за ребенком/ Spending time } \\
\text { of family members for the child care }\end{array}$} & \multirow[t]{3}{*}{ X6 } & Затраты времени матери & X13mtime \\
\hline & & & Затраты времени отца & X14ftime \\
\hline & & & Других членов семьи & X15othtime \\
\hline \multirow[t]{3}{*}{11} & \multirow{3}{*}{ Пособия/ Allowances } & \multirow[t]{3}{*}{$\mathrm{X} 7$} & Одно пособие & X1benefits \\
\hline & & & Два пособия & X2benefits \\
\hline & & & Три пособия & X3benefits \\
\hline \multirow[t]{4}{*}{12} & \multirow{4}{*}{$\begin{array}{l}\text { Характеристики семьи/ Family } \\
\text { characteristics }\end{array}$} & \multirow[t]{4}{*}{$\mathrm{X} 8$} & Среднедушевой доход & X22fam \\
\hline & & & Количество детей в семьи & X23fam \\
\hline & & & Субъект, заботящийся о ребенке & X24fam \\
\hline & & & Диагноз ребенка & X25diagnoz \\
\hline
\end{tabular}

Примечание - Составлено авторами

По результатам опроса, в программе SmartPLS построена структурная модель, которая представляет собой систему регрессионных уравнений, демонстрирующую цифровое выражение взаимосвязей между переменными. Преимущество метода состоит в том, что в рамках одной структурной модели можно оценить влияние совокупности факторов Xn на несколько зависимых переменных Ym, а также влияние переменных Ym друг на друга. Каждая переменная характеризуется через совокупность характеристик и оценивает влияние не каждого отдельного фактора, а всей совокупности признаков.

Метод PLS-PM позволяет оценивать сложные модели причинно-следственных связей со скрытыми переменными, которые значимы, но не наблюдаемы (например, мотивация респондентов, оценка ими событий, удовлетворенность респондента событием и т.п.). Преимуществом модели является возможность её использования в социологических опросах на небольших объемах выборки.

Метод включает два этапа:
1) Валидизация модели: конфирматорный факторный анализ (confirmatory factor analysis). На этом этапе проверяется адекватность построенной модели регрессионных уравнений статистическим критериям.

2) Тестирование структурной модели: путевой (path) анализ. На данном этапе формулируется и проверяется ряд гипотез, которые могут быть выдвинуты в рамках модели.

\section{Результаты}

Для выявления связей между зависимыми и независимыми переменными нами проведены расчеты в модели PLS-PM (рисунок 1).

Первый этап: Валидизация модели измерения.

Конфирматорный факторный анализ количественно описывает структуру данных модели. Оценка коэффициентов индикаторов модели на валидность показывает приемлемые показатели качества, так как большинство индикаторов для переменных X и Y в модели имеют значения выше 0,7. Это подтверждает корреляцию. 


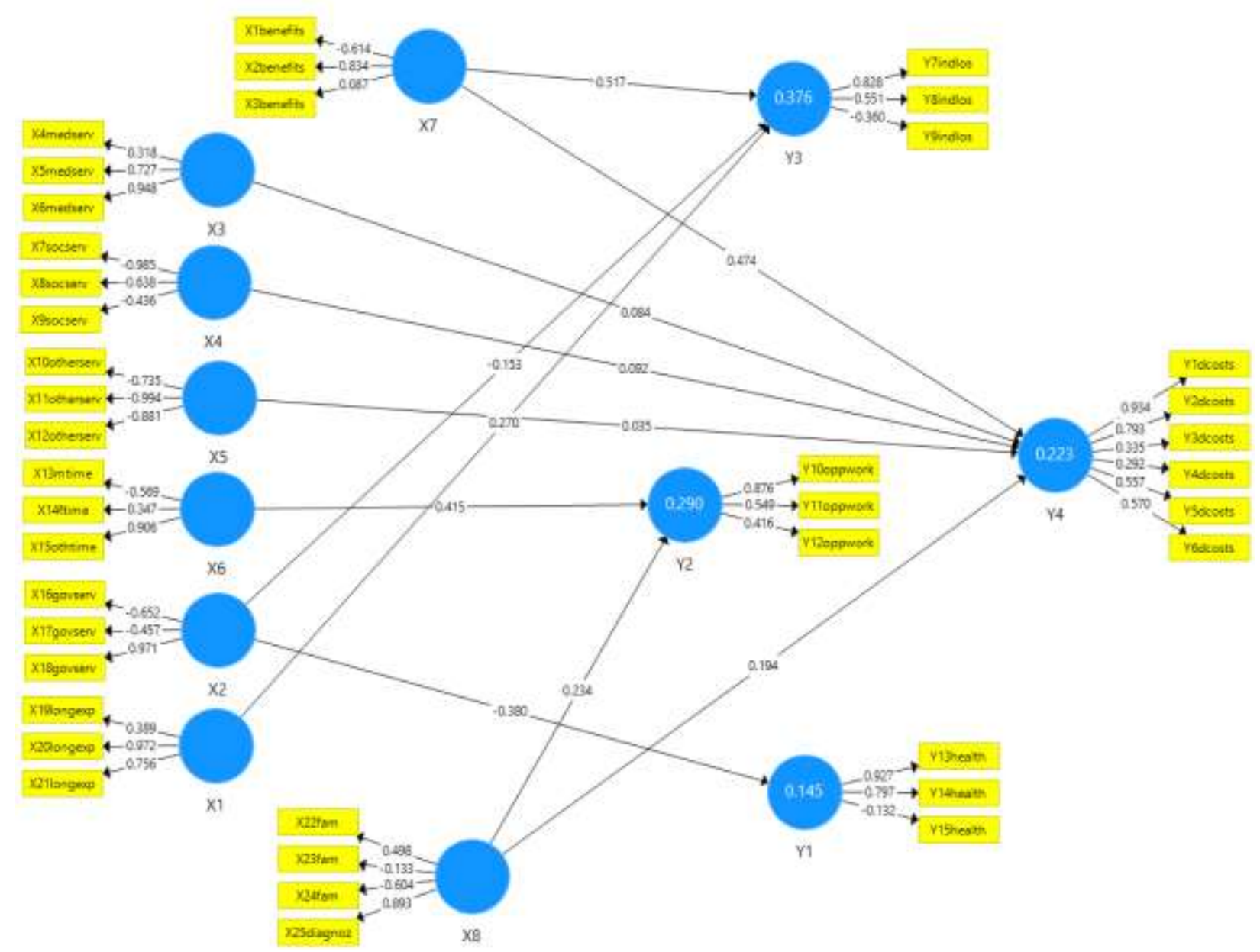

Рисунок 1 - Структурная модель для кейса «Неполная семья»

Figure 1 - Structural model for the case "Single family"

Примечание - Составлено авторами на основании анализа данных социологического опроса в программе SmartPLS

Проверка внутренней согласованности тестовых вопросов проверяется с помощью коэффициентов надежности и валидности, основным из которых является коэффициент Alpha Cronbach's (таблица 2).

Cronbach's Alpha коэффициент служит показателем однородности (внутренней согласованности) оценок индикаторов. Шкала коэффициента: 0,5 - низкая; 0,6 удовлетворительная; 0,7 - хорошая; 0,8 - очень хорошая; 0,9 - высокая.

Данные таблицы 2 показывают удовлетворительный уровень внутренней согласованности элементов теста и их влияние на факторы. Исключение составляют факторы: «Затраты времени на уход за ребенком», «Пособия», «Характеристики семьи», что объясняется высокой неоднородностью по- лученных ответов или наоборот чрезмерным сходством. Например, затраты времени на уход за ребенком в семьях значительно варьируются от 2 часов до 24 часов в день.

Коэффициент извлечения средней дисперсии (AVE) - это дисперсия элементов индикатора. Значение AVE должно быть 0,5 или больше, но меньше совокупной надежности (CR). То есть дисперсия, объясняемая конструкцией, должна быть больше ошибки измерения и больше перекрестных нагрузок. Так как AVE и соответствующие коэффициенты достоверности основаны на факторных нагрузках их значения варьируются в зависимости от факторной модели. AVE для фактора или скрытой переменной также должен быть выше, чем его квадрат корреляции с любым другим фактором или скрытой переменной. 
Таблица 2 - Коэффициенты надежности и валидности

Table 2 - Coefficients of reliability and validity

\begin{tabular}{|l|c|c|c|c|}
\hline \multicolumn{1}{|c|}{ Variables } & $\begin{array}{c}\text { Cronbach's } \\
\text { Alpha }\end{array}$ & rho_A & $\begin{array}{c}\text { Composite } \\
\text { Reliability }\end{array}$ & $\begin{array}{c}\text { Average Variance } \\
\text { Extracted (AVE) }\end{array}$ \\
\hline Возможность поддерживать здоровье & 0.692 & 0.773 & 0.712 & 0.504 \\
\hline Возможность работать & 0.591 & 0.494 & 0.658 & 0.514 \\
\hline Долгосрочные расходы на образование & 0.747 & 0.736 & 0.771 & 0.556 \\
\hline Дополнительные государственные услуги & 0.712 & 0.821 & 0.642 & 0.525 \\
\hline Доступность медицинских услуг & 0.862 & 0.722 & 0.730 & 0.509 \\
\hline Доступность социальных услуг & 0.782 & 0.762 & 0.747 & 0.523 \\
\hline Другие услуги для ребенка & 0.910 & 2.474 & 0.907 & 0.768 \\
\hline Затраты времени & 0.425 & 0.531 & 0.312 & 0.421 \\
\hline Косвенные потери & 0.636 & 0.615 & 0.556 & 0.473 \\
\hline Пособия & 0.371 & 0.433 & 0.047 & 0.360 \\
\hline Прямые расходы на ребенка & 0.682 & 0.736 & 0.768 & 0.882 \\
\hline Характеристики семьи & 0.396 & 0.411 & 0.443 & 0.357 \\
\hline
\end{tabular}

Примечание - Составлено авторами на основании анализа данных социологического опроса в программе SmartPLS

CR - это коэффициент надежности конструкции (Composite Reliability), определяющий совокупную надежность конструкции. Коэффициент рассчитывается с использованием квадрата суммы стандартизированных факторных нагрузок и суммы дисперсии ошибок. Значение CR находится в диапазоне от 0 до 1 . Коэффициент равный 1 соответствует абсолютной надежности. Пороговые значения CR: 0,6 - подходит для поисковых исследований, 0,7 - для подтверждающих исследований, 0,8 или выше - это хорошая надежность для подтверждающих исследований. Коэффициент CR должен превышать значение коэффициента AVE.

В целом, коэффициенты альфа Кронбаха, AVE, CR имеют достаточно высокие показатели, что говорит о приемлемой статистике пригодности.
Проверка коллинеарности.

Коллинеарность характеризует наличие линейной зависимости между переменными модели. Факторы, находящиеся в тесной связи, выводят из модели, так как нарушается условие независимости между объясняющими переменными. Остается в модели тот фактор, который при достаточно тесной связи с результатом имеет наименьшую тесноту связи с другими факторами.

Таблица 3 представляет полученную статистику коллинеарности. Для обнаружения мультиколлинеарности используется показатель VIF. Максимально допустимое значение данного показателя составляет -5 , а минимальный порог $-0,2$.

Данные таблицы 3 находятся в допустимом диапазоне значений, что указывает на отсутствие мультиколлинеарности между переменными.

Второй этап: тестирование структурной модели.

Bootstrapping тестирование подтверждает или опровергает поставленные в исследовании гипотезы (таблица 4).

В модели подтвердились 6 гипотез из 11 возможных. 
Таблица 3 - Статистика коллинеарности

Table 3 - Collinearity statistics

\begin{tabular}{|l|c|c|c|c|}
\hline \multicolumn{1}{|c|}{ Факторы } & $\begin{array}{c}\text { Возможность } \\
\text { поддерживать } \\
\text { здоровье }\end{array}$ & $\begin{array}{c}\text { Возможность } \\
\text { работать }\end{array}$ & $\begin{array}{c}\text { Косвенные } \\
\text { потери }\end{array}$ & $\begin{array}{c}\text { Прямые } \\
\text { расходы на } \\
\text { ребенка }\end{array}$ \\
\hline Возможность поддерживать здоровье & & & & \\
\hline Возможность работать & & & 1.030 & 1.069 \\
\hline Долгосрочные расходы на образование & & & & 1.315 \\
\hline Дополнительные гос. услуги & 1.000 & & & 1.240 \\
\hline Доступность медицинских услуг & & & & 1.497 \\
\hline Доступность социальных услуг & & & & 1.119 \\
\hline Другие услуги & & & & 1.038 \\
\hline Затраты времени & & & & 1.136 \\
\hline Косвенные потери & & & & 1.119 \\
\hline Пособия & & & & \\
\hline Прямые расходы на ребенка & & & & \\
\hline Характеристики семьи & & & & \\
\hline
\end{tabular}

Примечание - Составлено авторами на основании анализа данных социологического опроса в программе SmartPLS

Таблица 4 - Коэффициенты пути

Table 4 - Path Coefficients

\begin{tabular}{|c|l|c|c|c|c|}
\hline \multicolumn{1}{|c|}{ № } & \multicolumn{1}{|c|}{ Гипотезы } & $\begin{array}{c}\text { Original } \\
\text { Sample }(\mathrm{O})\end{array}$ & $\begin{array}{c}\text { T Statistics } \\
(|\mathrm{O} / \mathrm{STDEV}|)\end{array}$ & P Values & $\begin{array}{c}\text { Статус } \\
\text { гипотезы }\end{array}$ \\
\hline 1 & $\begin{array}{l}\text { Долгосрочные расходы на образование -> } \\
\text { Косвенные потери }\end{array}$ & 0.270 & 1.995 & 0.049 & Принята \\
\hline 2 & $\begin{array}{l}\text { Дополнительные гос. услуги -> } \\
\text { Возможность поддерживать здоровье }\end{array}$ & -0.380 & 2.782 & 0.006 & Принята \\
\hline 3 & $\begin{array}{l}\text { Дополнительные гос. услуги -> Косвенные } \\
\text { Потери }\end{array}$ & -0.153 & 0.846 & 0.398 & Отклонена \\
\hline 4 & $\begin{array}{l}\text { Доступность медицинских услуг -> } \\
\text { Прямые расходы на ребенка }\end{array}$ & 0.084 & 0.598 & 0.550 & Отклонена \\
\hline 5 & $\begin{array}{l}\text { Доступность социальных услуг -> Прямые } \\
\text { расходы на ребенка }\end{array}$ & 0.092 & 0.649 & 0.516 & Отклонена \\
\hline 6 & $\begin{array}{l}\text { Другие услуги для ребенка-> Прямые } \\
\text { расходы на ребенка }\end{array}$ & 0.035 & 0.260 & 0.795 & Отклонена \\
\hline 7 & Затраты времени -> Возможность работать & 0.415 & 4.454 & 0.000 & Принята \\
\hline 8 & Пособия -> Косвенные потери & 0.517 & 2.643 & 0.008 & Принята \\
\hline 9 & Пособия -> Прямые расходы на ребенка & 0.474 & 5.826 & 0.000 & Принята \\
\hline 10 & $\begin{array}{l}\text { Характеристики семьи -> Возможность } \\
\text { работать }\end{array}$ & 0.234 & 1.986 & 0.048 & Принята \\
\hline 11 & $\begin{array}{l}\text { Характеристики семьи -> Прямые расходы } \\
\text { на ребенка }\end{array}$ & 0.194 & 0.986 & 0.324 & Отклонена \\
\hline
\end{tabular}

Примечание - Составлено авторами на основании анализа данных социологического опроса в программе SmartPLS

Содержательная оценка полученных результатов.

1) Y4 - Прямые затраты - зависимая величина с коэффициентом R Square $=0,223$. Коэффициент детерминации показывает, что все рассмотренные в данной модели переменные влияют на прямые затраты на
22-23\%. Невысокая величина Y4 для группы неполных семей, по сравнению со всей группой респондентов (38\%) [42], связана с тем, что в неполных семьях ярко выраженная зависимость от пособий, которых хватает только на удовлетворение первичных нужд. Поскольку семья неполная, то инвалидность 
ребенка и последующее прекращение или сокращение занятости матери радикально сказывается на совокупном доходе. Если семья живет только на пособия, то суммарная их величина находится в диапазоне 90-100 тысяч тенге. В большинстве семей просто не остается ресурсов после удовлетворения первичных жизненных потребностей (питание, коммунальные платежи, одежда) или их величина незначительна.

Из всех факторов влияния на прямые затраты наибольшую силу имеют пособия, выплачиваемые детям-инвалидам и лицам, ухаживающим за ними. Гипотеза 9 «Пособия => Прямые затраты на ребенка» принимается и имеет идеальное значение P Values $=0,000$, что подтверждает ограниченность ресурсов в неполных семьях.

Если для всей совокупности опрошенных домохозяйств сила влияния пособий (X1-X3benefits) на прямые затраты слаба, коэффициент равен 0,098, то для группы неполных домохозяйств сила влияния почти в пять раз выше, коэффициент 0,474. То есть неполные домохозяйства оценивают значение пособий для прямых затрат на нужды ребенка в 4,7 выше, чем полные семьи.

Внутри прямых затрат для неполных семей гораздо более значимы затраты:

- на транспортные и жилищные услуги (0,570 против 0,165 для всех семей);

- на развивающие и спортивные услуги (0,557 против 0,309 для всех семей);

- на специальные социальные услуги (0,335 против 0,116 для всех семей).

Эти домохозяйства выше оценивают объем, качество и режим предоставления государственных бесплатных услуг для ребенка, поскольку альтернативные рыночные услуги для них недоступны. Связь с прямыми затратами есть, хоть и величина её мала. Медицинские (X4-X6:0,084), социальные специальные (X7-X9:0,092) и другие услуги для ребенка (X10-12:0,035) имеют положительный коэффициент влияния на прямые затраты. То есть семьи несут дополнительные затраты при получении услуг и благ от государства. В частности, респонденты отмечают высокую стоимость некоторых лекарств, которые приходится покупать самим, и оплату пребывания в реабилитационном детском стационаре для матери, в то время как некоторые дети по жизненным показаниям не могут находиться там одни.

Из характеристик семьи самым значимым фактором, влияющим на прямые затраты, является диагноз ребенка (X25diagnoz:0,893). $\mathrm{Ha} \quad 90 \%$ прямые затраты обусловлены конкретным диагнозом и его тяжестью. Но сила влияния характеристик семьи составляет 0,194, что опять же незначительно в связи с тем, что финансовые ресурсы семьи в целом ограничены, и семьи чаще всего выбирают вариант действий «нет возможности».

2) Y2 - Косвенные потери на 38\% объясняются в рамках модели. Косвенные потери семьи обусловлены в $82 \%$ случаев тем, что один из родителей оставил (сократил) работу и произошло сокращение дохода семьи.

Самая сильная связь у косвенных потерь с пособиями, коэффициент равен 0,517. Гипотеза 8 подтверждается P Values $=0,008$. Оценка родителями пособий как источника замещения утраченных доходов понятна. Но значимость трансфертов у группы неполных семей в полтора раза выше, чем у всей группы респондентов, где она составила 0,339.

Характер связи между услугами государства для семьи в целом (краткосрочная и долгосрочная «социальная передышка») и косвенными потерями представлен отрицательным с коэффициентом -0,153. Гипотеза не имеет статистической значимости, но можно сделать вывод, что напряженность и пессимизм по отношению к объему доступных государственных услуг у части родителейодиночек проявляется.

Подтверждается гипотеза 1 о связи «Оценка долгосрочных расходов на образование $\Rightarrow$ Косвенные потери», т.к. Р Values $=0,049$. Родители в неполных семьях ощущают более остро ответственность за долгосрочные перспективы ребенка, есть коэффициент связи с косвенными потерями 0,270. Потенциальная способность долгосрочных расходов на образование ребенка в перспективе снижать косвенные потери семьи осознается. У всей группы домохозяйств эта связь, как значимая, не выявлена.

3) $Y 3$ - Возможсность работать. Эта зависимая переменная на $30 \%$ описывается параметрами модели, из которых самое сильное влияние имеет время, затрачиваемое на уход за ребенком. Гипотеза 7 подтверждается c идеальным значением $\mathrm{P}$ Values $=0,000$. Поскольку неполная семья чаще находится в особенно жестких финансовых ограничениях по сравнению с обычной, то значимость работы и дохода от нее оценивается респондентами высоко. И если время ухода менее 4 часов в день, то родитель, как правило, работает. Имеют значимое влияние характеристики семьи, особенно диагноз ребенка с коэффициентом 0,893 против 0,323 в случае всей группы. Подтверждается гипотеза 10 «Характеристики семьи $\Rightarrow$ Возможность работать» с P Values=0,048. 
4) Y4 - Возможность поддержнивать свое здоровье. Эта зависимая переменная имеет самый слабый потенциал объяснения внутри модели: 14-15\%. Наибольшее отрицательное влияние на неё из включенных в модель факторов оказывают государственные бесплатные услуги, оказываемые для семьи, а точнее их отсутствие. Связь характеризуется коэффициентом -0,380, т.е. оценка доступности государственных услуг для матери отрицательная, что, безусловно, является проблемой. В реальности отсутствуют бесплатные государственные услуги рекреационного, психологического, физиологического характера для родителей из неполных семей, недостаток которых для здоровья ощущается достаточно остро. В то время как вся группа респондентов оценивает отдельные виды услуг положительно, неполным семьям этих мер поддержки точно не хватает. Гипотеза 1 «Дополнительные государственные услуги $=>$ Возможность поддерживать здоровье» подтверждается P Values=0,006 с отрицательной оценкой влияния.

Обсуждение. В семейной политике развитых стран мира доминирует подход создания единого базового комплекса мер поддержки семьи, который дополняется пособиями и/или услугами в случае появления дополнительных социальных рисков [1, с.5].

Большинство стран ОЭСР в течение двух десятилетий 21 века ввели в систему меры финансовой и нефинансовой поддержки неполных семей с детьми, т.к. удельный вес таких семей и детей увеличился до 20\% и выше. Ряд стран применяет универсальное пособие по уходу для неполных семей с детьми-инвалидами, повышая его на 11-30\%, без проверки и с проверкой на доход. Другие страны рассматривают случай каждой семьи индивидуально и на местном уровне делают надбавки.

Наше выборочное исследование подтверждает, что, несмотря на невысокую долю семей с одним взрослым среди домохозяйств с детьми в Казахстане (8,3\%), неполные семьи с детьми-инвалидами являются статистически значимой группой в своей категории. Таких семей в нашей выборке оказалось 26\%.

В одном из последних европейских исследований показано, что $20 \%$ семей с детьми-инвалидами живет на трансферты [43]. В нашем исследовании из 78 неполных семей таких оказалось $37 \%$.

Мы подтверждаем многочисленные свидетельства исследователей Стабиле М., Аллин С. [44], Лукемейер А., Мейерс М., Смеединг Т. [45], определяющих, что семьи с детьми-инвалидами несут прямые затраты на получение ребенком реабилитационных услуг. Согласно результатам структурного моделирования, у казахстанских семей затраты «из своего кармана» имеют место на все виды реабилитационных услуг. Это тоже подтверждается результатами исследований, согласно которым в ОЭСР $68 \%$ семей с детьми-инвалидами доплачивают из своих средств за услуги [43].

Объем и структура затрат в разных странах различается, но многие исследователи, в частности, Хайнц-Мартин В., Лангмейер А. [10] отмечают трудности в оплате дополнительных услуг для детей, коммунальных услуг и полноценного питания, что также подтверждается нашими результатами.

Значимость реализации в государственных реабилитационных структурах технологий вывода ребенка с инвалидностью в самостоятельную жизнь, в том числе для сокращения косвенных затрат семьи в перспективе, подтверждается в исследованиях Олссон М., Хван С. [46],

В результатах многих исследований, например, Перри-Дженкинс М., Гиллман С. [13], последствия для благосостояния от занятости родителей в семьях с детьмиинвалидами не имеют однозначной положительной оценки. Согласно нашим peзультатам, семьи с занятым родителем однозначно имеют более высокий уровень дохода, если родитель имеет возможность выйти на работу, хотя бы и в режиме нестандартной занятости.

Мы согласны с Чаплинской Е. [47], что доступная услуга краткосрочной «социальной передышки» будет значима для категории неполных семей, не имеющих возможности рассчитывать на помощь членов расширенной семьи (бабушек, дедушек и т.п.). А долгосрочная «социальная передышка» будет востребована всеми семьями.

\section{Выводы}

Для большинства неполных семей экономические и социальные ограничения в развитии человеческого капитала детей и родителей имеют более жесткий характер, чем для обычного домохозяйства. В этих семьях сочетаются два общепризнанных социальных риска: инвалидность ребенка и один взрослый член нуклеарной семьи, который в случае средних или тяжелых диагнозов ребенка может утратить источник трудовых доходов и возможность поддерживать свое здоровье.

Согласно результатам опроса, $37 \%$ неполных семей живет только на трансферты 
государства и алименты, $28 \%$ имеет среднедушевые доходы ниже прожиточного минимума.

Структурная модель для кейса «Неполные семьи» позволила верифицировать 6 гипотез.

1. Результаты расчетов в программе SmartPLS подтверждают, что прямые затраты на реабилитационные услуги для ребенка в той или иной мере несут $93 \%$ семей. Статистически значимое влияние на прямые затраты имеют государственные пособия, выплачиваемые детям с инвалидностью и лицам, ухаживающим за ними. Гипотеза о влиянии пособий на прямые затраты подтверждена. Получение трансфертов для $37 \%$ таких семей жизненно важно, т.к. они являются единственным источником жизненных ресурсов. Значение трансфертов для прямых затрат семьи на ребенка респонденты оценивают в четыре раза выше, чем полные семьи. Решить или смягчить проблему может дополнительное пособие по уходу за ребенком для родителей-одиночек, для получения которого может использоваться проверка на доход. Размер пособия рекомендуется не менее чем один прожиточный минимум.

2. Подтверждены две гипотезы о связи пособий и прогнозной оценки долгосрочных расходов на ребенка с косвенными потерями семьи.

Когда пособия становятся единственным источником дохода, то косвенные потери от снижения доходов семьи в результате сокращения/прекращения занятости матери оцениваются респондентами выше, чем в общем случае для стандартной семьи с двумя родителями. Пособия рассматриваются с точки зрения замещения утраченного дохода, а в настоящее время размер пособий по уходу чаще всего не компенсирует утраченный доход и затраты на долгосрочную социальную передышку. Для снижения косвенных потерь целесообразно введение государственной услуги долгосрочной «социальной передышки» для отдыха и лечения родителя, стандарт которой будет нами разработан в дальнейшей работе.

Родители из неполных семей чаще, чем полных, связывают предполагаемые ими долгосрочные расходы своей семьи на будущее ребенка (профобразование, жилье) и косвенные потери семьи. Есть четкое понимание значимости таких расходов для снижения косвенных потерь семьи в перспективе. Необходимо отметить, что для полных семей эта связь вообще не выявлена.
Решение или смягчение остроты проблемы может быть связано с реализацией социальными службами технологии вывода ребенка в самостоятельную жизнь, что требует разработки методики и стандарта такой услуги, что и будет сделано нами в последующих работах.

3. Подтверждаются две гипотезы, связанные с возможностью работы для члена семьи, который обеспечивает уход за ребенком. Здесь принципиальное значение имеет время, которое тратит родитель на уход за ребенком и характеристики семьи, в том числе диагноз ребенка. Для решения или смягчения проблемы целесообразно ориентировать Центры занятости на адресную работу с этой целевой группой и предложение для родителей вариантов неполной или надомной занятости, в том числе на социальных рабочих местах.

4. Выявлена статистически значимая отрицательная связь между доступными услугами (государственными или субсидируемыми государством) для родителя в области здоровья физиологического/психического и оценкой родителя возможности поддерживать здоровье. В настоящее время у родителя нет возможности по льготным ценам или бесплатно получать психологические услуги, посещать оздоровительные или лечебные мероприятия, поддерживающие психическое и физическое состояние здоровья. Для неполных семей наличие таких льгот имеет принципиальное значение и в дальнейшем будут разработаны варианты их получения.

\section{Список использованных источников:}

1. Rimmerman, A. (2015). Family Policy and Disability. Cambridge: Cambridge University Press, $226 \mathrm{p}$.

2. OECD Family Database. [Electronic source]. URL: $\quad$ https://www.oecd.org/els/family/SF_1_1 Family size and composition.xlsx (date of access: 08.08.2021)

3. OECD Family Database. [Electronic source]. URL: https://www.oecd.org/els/soc/SF 12 Childrenin families.xlsx (date of access: 08.08.2021)

4. OECD Family Database. [Electronic source]. URL: https://www.oecd.org/els/soc/PF1 3 Family Cash_Benefits.xlsx (date of access: 10.08.2021)

5. OECD Family Database. [Electronic source]. URL: $\quad$ https://www.oecd.org/els/family/CO1.9\%20 Child\%20 disability\%20FINAL.xls (date of access: 11.08.2021)

6. Бюро национальной статистики Агентства по стратегическому планированию и реформам Республики Казахстан. [Электронный 
pecypc]. URL: https://stat.gov.kz/official/industry/64/ statistic/5 (дата обращения: 08.09.2021)

7. Бюро национальной статистики Агентства по стратегическому планированию и реформам Республики Казахстан. [Электронный pecypc]. URL: https://bala.stat.gov.kz/kolichestvopoluchatelej-posobij-po-uhodu-za-rebenkom/ (дата обращения: 08.09.2021)

8. Forry, N.D. (2009). The Impact of Child Care Subsidies on Low-Income Single Parents: An Examination of Child Care Expenditures and Family Finances. Journal of Family and Economic Issues, 30, 43-54. https://doi.org/10.1007/s10834-008-9135-6

9. Stack, R., Meredith, A. (2018). The Impact of Financial Hardship on Single Parents: An Exploration of the Journey From Social Distress to Seeking Help. Journal of Family and Economic Issues, 39, 233-242. https://doi.org/10.1007/s10834-017-9551-6

10. Heintz-Martin, V., Langmeyer, A. (2020). Economic Situation, Financial Strain and Child Wellbeing in Stepfamilies and Single-Parent Families in Germany. Journal of Family and Economic Issues, 41, 238-254. https://doi.org/10.1007/s10834-019-09653-z

11. Brown, S., Manning, W., Stykes, J. (2015). Family structure and child well-being: Integrating family complexity. Journal of Marriage and the Family, 77, 177-190. https://doi.org/10.1111/jomf.12145

12. Campbell, M., Thomson, H., Fenton, C. (2016). Lone parents, health, wellbeing and welfare to work: a systematic review of qualitative studies. BMC Public Health, 16, 188-201. https://doi.org/10.1186/ s12889-016-2880-9

13. Perry-Jenkins M., Gillman S. (2000). Parental Job Experiences and Children's Well-Being: The Case of Two-Parent and Single-Mother WorkingClass Families. Journal of Family and Economic Issues, 21, 123-147. https://doi.org/10.1023/A:1009473918629

14. Gennetian, L. (2005). One or two parents? Half or step siblings? The effect of family structure on young children's achievement. Journal of Population Economics, 18, 415-436. https://doi.org/10.1007/ s00148-004-0215-0

15. Härkönen, J., Bernardi, F., Boertien, D. (2017). Family Dynamics and Child Outcomes: An Overview of Research and Open Questions. European Journal of Population, 33, 163-184. https://doi. org/10.1007/s10680-017-9424-6

16. Mariani, E., Özcan, B., Goisis, A. (2017). Family trajectories and wellbeing of children born to lone mothers in the United Kingdom. European Journal of Population, 33, 185-215. https://doi.org/10.1007/ s10680-017-9420-x

17. Radl, J., Salazar, L., Cebolla-Boado H. (2017). Does living in a fatherless household compromise educational success? A Comparative Study of Cognitive and Non-Cognitive Skills. European Journal of Population, 33, 217-242. https://doi. org/10.1007/s10680-017-9414-8

18. Penne, T., Hufkens, T., Goedemé, T., Storms, B. (2020).To what extent do welfare states compensate for the cost of children? The joint impact of taxes, benefits and public goods and services. Journal of European Social Policy, 30(1), 79-94. https://doi. org/10.1177/0958928719868458
19. Cullinan, J., Gannon, B., Lyons, S. (2011). Estimating the extra cost of living for people with disabilities. Health Economics, 20(5), 582-599. https:// doi.org/10.1002/hec.1619

20. Mitra, S. (2017). Extra costs of living with a disability: A review and agenda for research. Disability and Health Journal, 10(4), 475-484. http:// dx.doi.org/10.1016/j.dhjo.2017.04.007

21. Daly, M., Grace, K. (2015). Families and Poverty: Everyday Life on a Low Income. Bristol: Policy Press, 272.

22. Preston, G. (2006). Families with disabled children, benefits and poverty. The Journal of Poverty and Social Justice, 14(1), 39-43.

23. La Placa, V., Corlyon, J. (2016). Unpacking the Relationship between Parenting and Poverty: Theory, Evidence and Policy. Social Policy and Society, 15(1), 11-28. doi: 10.1017/S1474746415000111

24. Braithwaite, J., Mont, D. (2009). Disability and poverty: a survey of World Bank poverty assessments and implications. ALTER - European Journal of Disability Research / Revue Européenne de Recherche sur le Handicap, 3(3), 219-232.

25. Loprest, P., Davidoff, A. (2004). How Children with Special Health Care Needs Affect the Employment Decisions of Low-Income Parents. Matern Child Health Journal, 8(3), 171-182. doi: 10.1023/B:M ACI.0000037650.83572.81

26. Maklanahan, S. (2012). Children with disability. The Future of Children, 22(1), Princeton Booking, Washington D.C., 222.

27. Daly, M. (2010). Shifts in family policy in the UK under New Labour. Journal of European Social Policy, 20, 433-443.

28. Family Policy in the 28 EU Member States. Taskforce on European and International Relations and Cooperation Country Overview. July, 2015. [Electronic source]. URL: https:/www.caf.fr/sites/default/ files/cnaf/Documents/international/fiches $\% 20$ pays/ Compil\%20fiches\%20pays \%20pays\%20UE_01\%20 2018_English.pdf (date of access: 15.09.2021)

29. Morris, Z. (2020). The extra costs associated with living with a disability in the U.S. Working paper. [Electronic source]. URL: https:// www.nationaldisabilityinstitute.org/reports/extra-costsliving-with-disability/ (date of access: 16.09.2021)

30. Okon, M., Henderson A., Kinnear D., Cooper Sally-Ann. (2019). Trends and variations in per capita expenditure on adult intellectual disabilities health and social care across Scotland, and by urban/ rural class. Journal of Applied Research in Intellectual Disabilities, 32(1), 121-130. doi: 10.1111/jar.12514

31. Zaidi, A., Burchardt, T. (2005). Comparing incomes when needs differ: equivalization for the extra costs of disability in the UK. The Review of Income and Wealth, 51(1), 89-114. doi:10.1111/j.14754991.2005.00146.x

32. Morris, Z., Zaidi, A. (2020). Estimating the extra costs of disability in European countries: Implications for poverty measurement and disabilityrelated decommodification. Journal of European Social Policy, 30(3), 339-354. doi: 10.1177/09589287198 91317 
33. Bourke-Taylor, H., Cotter, C., Stephan, R. (2014). Young children with cerebral palsy: families self-reported equipment needs and out-of-pocket expenditure. Child: Care, Health and Development, 40(5), 654-662. https://doi.org/10.1111/cch.12098

34. Coleridge, P. (2005). Disabled people and 'employment' in the majority world: policies and realities. Bristol, Policy Press, 368.

35. Anderson, L. (2018). Family and Individual Needs for Disability Supports. Minnesota: Research and Training Center on Community Living, Institute on Community Integration, University of Minnesota, 25.

36. Lindqvist, R. (2000). Swedish Disability Policy: From Universal Welfare to Civil Rights? European Journal of Social Security, 2(4), 399-418. doi: 10.1023/A:1011532222021

37. Emerson, E. (2006). Socio -economic position, household composition, health status and indicators of the well-being of mothers of children with and without intellectual disabilities. Journal of Intellectual Disability Research, 50 (12), 862-873. doi:10.1111/j.1365-2788.2006.00900.x

38. Темирбаева Д. (2017). Классификация моделей и механизмов семейной политики в развитых странах. Вестник КарГУ. Серия экономика, 3, 201-208.

39. Gooding, K., Marriot, A. (2009) Including persons with disabilities in social cash transfer programmes in developing countries. Journal of International Development, 21(5), 685-698. http:// dx.doi.org/10.1002/jid.1597

40. Valls, F.F., Belzunegui, E.Á., De Andrés S.J. (2020). Efficiency of Social Expenditure Levels in Reducing Poverty Risk in the EU-28. Poverty \& Public Policy, 12(1), 43-62. doi: 10.1002/pop4.267.

41. Parish, S. (2008). Material Hardship in U.S. Families Raising Children with Disabilities. Exceptional Children, 75(1), 71-92. doi: 10.1177/001440290807500104

42. Притворова Т.П., Аяганова М.П. (2021). Семьи с ограниченными возможностями: прямые расходы, трансферты и доступные услуги. Экономика Центральной Азии, 5, 2, 193-206. doi: 10.18334/asia.5.2.112052.

43. Giulio, P., Philipov, D., Jaschinski, I. (2014). Families with disabled children in different European countries. Families and Societies. Working Paper Series, 23. URL: http://www.familiesandsocieties. eu/wp-content/uploads/2014/12/WP23GiulioEtAl.pdf

44. Stabile, M., Allin, S. (2012). The economic costs of childhood disability. Future Child, 22(1), 65-96.

45. Lukemeyer,Anna., Meyers, M., Smeeding, T. (2000). Expensive Children in Poor Families: Outof-Pocket Expenditures for the Care of Disabled and Chronically Ill Children in Welfare Families. Journal of Marriage and Family, 62(2), 399-415. doi: 10.1111/j.1741-3737.2000.00399.x.

46. Olsson, M., Hwang, C. (2006). Wellbeing, involvement in paid work and division of child-care in parents of children with intellectual disabilities in Sweden. Journal of Intellectual Disability Research, 50(12), 963-969. doi: 10.1111/j.13652788.2006.00930.x
47. Чаплинская Е.В. (2013). Социальная реабилитация семей, имеющих детей-инвалидов, как технология социальной работы. Наука и современность, 21, 108-113.

\section{References}

1. Rimmerman, A. (2015). Family Policy and Disability. Cambridge: Cambridge University Press, $226 \mathrm{p}$.

2. OECD Family Database. [Electronic source]. URL: $\quad$ https://www.oecd.org/els/family/SF 11 Family size and composition.xlsx (date of access: 08.08.2021)

3. OECD Family Database. [Electronic source]. URL: https://www.oecd.org/els/soc/SF 12 Children in families.xlsx (date of access: 08.08.2021)

4. OECD Family Database. [Electronic source]. URL: https://www.oecd.org/els/soc/PF1 3 Family Cash_Benefits.xlsx (date of access: 10.08.2021)

5. OECD Family Database. [Electronic source]. URL: $\quad$ https://www.oecd.org/els/family/CO1.9\%20 Child\%20 disability\%20FINAL.xls (date of access: 11.08.2021)

6. Bjuro nacional'noj statistiki Agentstva po strategicheskomu planirovaniju i reformam Respubliki Kazahstan. [Electronic source]. URL: https://stat. gov.kz/official/industry/64/statistic/5 (date of access: 08.09.2021)

7. Bjuro nacional'noj statistiki Agentstva po strategicheskomu planirovaniju i reformam Respubliki Kazahstan. [Electronic source]. URL: https://bala.stat. gov.kz/kolichestvo-poluchatelej-posobij-po-uhodu-zarebenkom/ (date of access: 08.09.2021)

8. Forry, N.D. (2009). The Impact of Child Care Subsidies on Low-Income Single Parents: An Examination of Child Care Expenditures and Family Finances. Journal of Family and Economic Issues, 30, 43-54. https://doi.org/10.1007/s10834-008-9135-6

9. Stack, R., Meredith ,A. (2018). The Impact of Financial Hardship on Single Parents: An Exploration of the Journey From Social Distress to Seeking Help. Journal of Family and Economic Issues, 39, 233-242. https://doi.org/10.1007/s10834-017-9551-6

10. Heintz-Martin, V., Langmeyer, A. (2020). Economic Situation, Financial Strain and Child Wellbeing in Stepfamilies and Single-Parent Families in Germany. Journal of Family and Economic Issues, 41, 238-254. https://doi.org/10.1007/s10834-019-09653-z

11. Brown, S., Manning, W., Stykes J. (2015). Family structure and child well-being: Integrating family complexity. Journal of Marriage and the Family, 77, 177-190. https://doi.org/10.1111/jomf.12145

12. Campbell, M., Thomson, H., Fenton, C. (2016). Lone parents, health, wellbeing and welfare to work: a systematic review of qualitative studies. BMC Public Health, 16, 188-201. https://doi.org/10.1186/ s12889-016-2880-9

13. Perry-Jenkins, M., Gillman, S. (2000). Parental Job Experiences and Children's Well-Being: The Case of Two-Parent and Single-Mother WorkingClass Families. Journal of Family and Economic Issues, 21, 123-147. https://doi.org/10.1023/A:1009473918629 
14. Gennetian, L. (2005). One or two parents? Half or step siblings? The effect of family structure on young children's achievement. Journal of Population Economics, 18, 415-436. https://doi.org/10.1007/ s00148-004-0215-0

15. Härkönen, J., Bernardi, F., Boertien, D. (2017). Family Dynamics and Child Outcomes: An Overview of Research and Open Questions. European Journal of Population, 33, 163-184. https://doi. org/10.1007/s10680-017-9424-6

16. Mariani, E., Özcan, B., Goisis, A. (2017). Family trajectories and wellbeing of children born to lone mothers in the United Kingdom. European Journal of Population, 33, 185-215. https://doi.org/10.1007/ s10680-017-9420-x

17. Radl, J., Salazar, L., Cebolla-Boado, H. (2017). Does living in a fatherless household compromise educational success? A Comparative Study of Cognitive and Non-Cognitive Skills. European Journal of Population, 33, 217-242. https://doi. org/10.1007/s10680-017-9414-8

18. Penne, T., Hufkens, T., Goedemé, T., Storms, B. (2020).To what extent do welfare states compensate for the cost of children? The joint impact of taxes, benefits and public goods and services. Journal of European Social Policy, 30(1), 79-94. https://doi. org/10.1177/0958928719868458

19. Cullinan, J., Gannon, B., Lyons, S. (2011). Estimating the extra cost of living for people with disabilities. Health Economics, 20(5), 582-599. https:// doi.org/10.1002/hec.1619

20. Mitra, S. (2017). Extra costs of living with a disability: A review and agenda for research. Disability and Health Journal, 10(4), 475-484. http:// dx.doi.org/10.1016/j.dhjo.2017.04.007

21. Daly M., Grace K. (2015). Families and Poverty: Everyday Life on a Low Income. Bristol: Policy Press, 272 .

22. Preston, G. (2006). Families with disabled children, benefits and poverty. The Journal of Poverty and Social Justice, 14(1), 39-43.

23. La Placa, V., Corlyon, J. (2016). Unpacking the Relationship between Parenting and Poverty: Theory, Evidence and Policy. Social Policy and Society, 15(1), 11-28. doi: 10.1017/S1474746415000111

24. Braithwaite, J., Mont ,D. (2009). Disability and poverty: a survey of World Bank poverty assessments and implications. ALTER - European Journal of Disability Research / Revue Européenne de Recherche sur le Handicap, 3(3), 219-232.

25. Loprest, P., Davidoff, A. (2004). How Children with Special Health Care Needs Affect the Employment Decisions of Low-Income Parents. Matern Child Health Journal, 8(3), 171-182. doi: 10.1023/B:M ACI.0000037650.83572.81

26. Maklanahan, S. (2012). Children with disability. The Future of Children, 22(1), Princeton Booking, Washington D.C., 222 .

27. Daly, M. (2010). Shifts in family policy in the UK under New Labour. Journal of European Social Policy, 20, 433-443.

28. Family Policy in the 28 EU Member States. Taskforce on European and International Relations and Cooperation Country Overview. July,
2015. [Electronic source]. URL: https://www.caf. $\mathrm{fr} /$ sites/default/files/cnaf/Documents/international/ fiches $\% 20$ pays $/$ Compil $\% 20$ fiches $\% 20$ pays $\% 20$ pays\%20UE_01\%202018_English.pdf (date of access: 15.09.2021)

29. Morris, Z. (2020). The extra costs associated with living with a disability in the U.S. Working paper. [Electronic source]. URL: https:// www.nationaldisabilityinstitute.org/reports/extra-costsliving-with-disability/ (date of access: 16.09.2021)

30. Okon, M., Henderson, A., Kinnear, D., Cooper Sally-Ann. (2019). Trends and variations in per capita expenditure on adult intellectual disabilities health and social care across Scotland, and by urban/ rural class. Journal of Applied Research in Intellectual Disabilities, 32(1), 121-130. doi: 10.1111/jar.12514

31. Zaidi, A., Burchardt, T. (2005). Comparing incomes when needs differ: equivalization for the extra costs of disability in the UK. The Review of Income and Wealth, 51(1), 89-114. doi:10.1111/j.14754991.2005.00146.x

32. Morris, Z., Zaidi, A. (2020). Estimating the extra costs of disability in European countries: Implications for poverty measurement and disabilityrelated decommodification. Journal of European Social Policy, 30(3), 339-354. doi: 10.1177/09589287198 91317

33. Bourke-Taylor, H., Cotter, C., Stephan, R. (2014). Young children with cerebral palsy: families self-reported equipment needs and out-of-pocket expenditure. Child: Care, Health and Development, 40(5), 654-662. https://doi.org/10.1111/cch.12098

34. Coleridge, P. (2005). Disabled people and 'employment' in the majority world: policies and realities. Bristol, Policy Press, 368.

35. Anderson, L. (2018). Family and Individual Needs for Disability Supports. Minnesota: Research and Training Center on Community Living, Institute on Community Integration, University of Minnesota, 25.

36. Lindqvist, R. (2000). Swedish Disability Policy: From Universal Welfare to Civil Rights? European Journal of Social Security, 2(4), 399-418. doi: 10.1023/A:1011532222021

37. Emerson, E. (2006). Socio -economic position, household composition, health status and indicators of the well-being of mothers of children with and without intellectual disabilities. Journal of Intellectual Disability Research, 50 (12), 862-873. doi:10.1111/j.1365-2788.2006.00900.x

38. Temirbaeva, D. (2017). Klassifikacija modelej i mehanizmov semejnoj politiki $\mathrm{v}$ razvityh stranah. Vestnik KarGU. Serija jekonomika, 3, 201-208. (in Russ.)

39. Gooding, K., Marriot, A. (2009). Including persons with disabilities in social cash transfer programmes in developing countries. Journal of International Development, 21(5), 685-698. http:// dx.doi.org/10.1002/jid.1597

40. Valls, F.F., Belzunegui, E.Á., De Andrés, S.J. (2020). Efficiency of Social Expenditure Levels in Reducing Poverty Risk in the EU-28. Poverty \& Public Policy, 12(1), 43-62. doi: 10.1002/pop4.267.

41. Parish, S. (2008). Material Hardship in U.S. Families Raising Children with Disabilities. 
Exceptional Children, 75(1), 71-92. doi: 10.1177/001440290807500104

42. Pritvorova, T.P., Ajaganova, M.P. (2021) Sem'i s ogranichennymi vozmozhnostjami: prjamye rashody, transferty i dostupnye uslugi. Jekonomika Central'noj Azii, 5, 2, 193-206. doi: 10.18334/ asia.5.2.112052 (in Russ.)

43. Giulio, P., Philipov, D., Jaschinski, I. (2014). Families with disabled children in different European countries. Families and Societies. Working Paper Series, 23. URL: http://www.familiesandsocieties. eu/wp-content/uploads/2014/12/WP23GiulioEtAl.pdf

44. Stabile, M., Allin, S. (2012). The economic costs of childhood disability. Future Child, 22(1), 65-96.
45. Lukemeyer, Anna., Meyers, M., Smeeding, T. (2000). Expensive Children in Poor Families: Outof-Pocket Expenditures for the Care of Disabled and Chronically Ill Children in Welfare Families. Journal of Marriage and Family, 62(2), 399-415. doi: 10.1111/j.1741-3737.2000.00399.x.

46. Olsson, M., Hwang, C. (2006). Wellbeing, involvement in paid work and division of child-care in parents of children with intellectual disabilities in Sweden. Journal of Intellectual Disability Research, 50(12), 963-969. doi: 10.1111/j.13652788.2006.00930.x

47. Chaplinskaja, E.V. (2013). Social'naja reabilitacija semej, imejushhih detej-invalidov, kak tehnologija social'noj raboty. Nauka i sovremennost', 21, 108-113. (in Russ.)

\section{Information about the authors}

Tatyana P. Pritvorova - Doctor of Economics, professor, Karaganda university after E.A. Buketov, Kazakhstan, e-mail: pritvorova_@mail.ru, ORCID ID: https://orcid.org/0000-0002-6306-3960

* Assiya K. Atabayeva - Correspondent author, PhD student, Karaganda University named after E.A. Buketov, Kazakhstan, e-mail: asiaatabaeva@gmail.com, ORCID ID: https://orcid.org/0000-0002-4644- 1843

Yelena S. Petrenko - Doctor of Economics, professor, Plekhanov Russian University of Economics, Russia, e-mail: petrenko_yelena@bk.ru, ORCID ID:https://orcid.org/0000-0001-6892-2392

\section{Авторлар туралы мәліметтер}

Притворова Татьяна Петровна - экономика ғылымдарының докторы, профессор, Е.А.Бөкетов атындағы Қарағанды университеті, Қазақстан, e-mail: pritvorova_@mail.ru, ORCID ID: https: // orcid. org / 0000-00026306-3960

*Атабаева Асия Қайрошқызы - хат-хабаршы авторы, PhD-докторант, Е.А.Бөкетов атындағы Қарағанды университеті, Қазақстан, e-mail: asiaatabaeva@gmail.com, ORCID ID: https://orcid.org/0000-0002 - 4644-1843

Петренко Елена Степановна - экономика ғылымдарының докторы, профессор, Г.В. Плеханов атындағы Ресей экономика университеті, Ресей, e-mail: petrenko_yelena@bk.ru, ORCID: https: //orcid.org/0000-00016892-2392

\section{Сведения об авторах}

Притворова Татьяна Петровна - доктор экономических наук, профессор, Карагандинский университет имени Е.А.Букетова, Казахстан, e-mail: pritvorova_@mail.ru, ORCID ID: https://orcid.org/0000-0002-6306-3960

*Атабаева Асия Кайрошовна - PhD-докторант, КарУ имени Е. А Букетова, Казахстан, е-mail: asiaatabaeva@ gmail.com, ORCID ID: https://orcid.org/0000-0002-4644-1843

Петренко Елена Степановна - доктор экономических наук, профессор, Российский экономический университет им. Г.В. Плеханова, Россия, e-mail: petrenko_yelena@bk.ru, ORCID ID:https://orcid.org/0000-0001$6892-2392$ 